\title{
Knowledge, Attitude and Associated Factors towards Safe Abortion among Private College Female Students of Gondar town, northwest Ethiopia: A cross sectional study
}

Birye Dessalegn Mekonnen ( $\nabla$ birye22@gmail.com )

Tedda Health Science College https://orcid.org/0000-0001-7028-1723

Chalachew Adugna Wubneh

University of Gondar

Research article

Keywords: Knowledge, Attitude, Safe abortion, Factors, Students, Ethiopia

Posted Date: October 3rd, 2019

DOl: https://doi.org/10.21203/rs.2.15471/v1

License: (c) (1) This work is licensed under a Creative Commons Attribution 4.0 International License. Read Full License 


\section{Abstract}

Background: Unwanted pregnancies in youths and complications of induced abortions are an important health problem. Inadequate knowledge, unfavorable attitude towards safe abortion results in unsafe abortion. Most women die because of complications arising from unsafe abortion in developing countries are likely to have had little knowledge. Studies on knowledge, attitude and associated factors towards safe abortion among private college students are limited. Therefore, the aim of this study was to assess knowledge, attitude and associated factors towards safe abortion among private college female students in Gondar town, northwest Ethiopia

Methods: An institution based cross-sectional study was conducted from April 30, 2019 to May 30, 2019 among private college students in Gondar town. Data were collected from 633female students using selfadministered questionnaires by simple random sampling technique. Bivariable and multivariable logistic regression analysis was performed to identify association of dependent and independent variables using SPSS version 20.

Result: A total of 633 respondents participated in this study with the response rate of $97.7 \%$. Regarding the overall knowledge, 433(68.4\%) of students had good knowledge towards safe abortion. Age (AOR= $2.81,95 \% \mathrm{Cl}: 1.13,7.47)$, residence ( $\mathrm{AOR}=2.33,95 \% \mathrm{Cl}: 1.22,4.46)$, family education ( $\mathrm{AOR}=3.29,95 \% \mathrm{Cl}$ : $1.22,6.46)$ and ever heard about safe abortion, (AOR=4.31, 95\% Cl: 1.79, 10.33) were factors associated with knowledge of students on safe abortion. Regarding attitude, 361 (57\%) of students had favorable attitude towards safe abortion. Age (AOR=2.62, 95\% Cl: 1.70, 4.04) and residents (AOR=1.50, 95\% Cl: 1.04, 2.17) were factors significantly associated with attitude towards safe abortion.

Conclusion: More than half of the participants have good knowledge and attitude towards safe abortion but still significant proportion of students have poor knowledge and unfavorable attitude. Information, Education and Communications programs on youth reproductive health should be provided to address topics on safe abortion for students. Forums and panel discussions on safe abortion need to be undertaken especially, among youths and students who came from rural area.

\section{Background}

Abortion is the termination of pregnancy before fetal viability which can occur spontaneously due to complications during pregnancy or can be induced(1). Abortion is safe when performed by persons with the necessary training and skills, and in an environment meeting minimal medical standards or it can be defined as the termination of pregnancy before 28 weeks of gestational age by qualified and skilled persons using correct techniques in sanitary conditions(2).

Unwanted pregnancies in youths and complications of induced abortions are an important health problem in the world; in which each year, approximately 20 million abortions are performed worldwide, $95 \%$ of them in developing countries (3). Out of 4.2 million pregnancies, an estimated 420,000 induced 
abortions occurred in Ethiopia in 2016, with an annual abortion rate of 28 per 1,000 women aged 15-49 (4).

In the world daily 192 reproductive age women died because of complications arising from unsafe abortion, majority of this occurred in developing countries. Those women are likely to have poor knowledge towards safe abortion. Many of them are young age, maybe in their teens. Some of them may be raped, and others have exposed to unintended pregnancy due to failure of the contraceptive method they were using or the incorrect or inconsistent way they used it. Some of them lacked knowledge of methods to prevent unintended pregnancy or did not have the access for the service(5).

As evidences indicate in Ethiopia, about half of all pregnancies end with unsafe abortion as a result of inadequate information, unfavorable attitude towards safe abortion. A study conducted in Ethiopia revealed that the rate of abortion among students was found to be 65 per 1000 women, making it three fold the national rate of abortion for Ethiopia (23/1000 women aged 15-44); almost all of the abortions (96.9\%) were induced and only $16 \%$ were reported to be safe abortion(6). Similar study at other regions of Ethiopia showed that the knowledge and attitude in relation to safe abortion are limited among women (7). In previous studies so far conducted in Ethiopia tried to identify factors associated with knowledge and attitude of students toward safe abortion. Marital status, family income and educational status of the parents were associated with knowledge of safe abortion among University students whereas previous residence was associated with attitude $(7,8)$.

Safe abortion is an essential component of reproductive health care, which entails a range of medical and related health services, including counseling, contraception, and referrals to other reproductive healthcare services as appropriate $(9,10)$.However, access to safe abortion continues to depend on several factors such as, women's awareness of the law, shortage of safe abortion services provision and sociocultural pressures $(6,11,12)$.

College students are vulnerable to unplanned and unintended early sexual encounters which lead to unwanted pregnancies. They are therefore exposed to seek for induced abortion and candidates to suffer its complications(13). The students who undergo an induced abortion expose themselves to serious health risks such as hemorrhage, genital injuries, sepsis and death(14). These study participants were chosen, because young women in the college environment are away from home for the first time and become free to experiment sex without any parental supervision, especially in the study area students in private college are non-dormitories. There is limited information on knowledge, attitude and associated factors towards safe abortion among private college students. Therefore, the aim of this study was to assess knowledge, attitude and associated factors towards safe abortion among private college female students in Gondar town, northwest Ethiopia. Thus, this study may help to give an attention for the development of guideline and resources regarding information, education and communications (IEC) programs on youth reproductive health for college students.

\section{Methods}




\subsection{Study Design, Setting, period and participants}

An institutional based cross-sectional study was conducted from April 30, 2019 to May 30, 2019 among private college students in Gondar town. This town is located in Amhara Regional State of northwest Ethiopia. During the study period there were four private colleges in the town. The total students enrolled in a regular program, during the study period, was 5,448. Out of these, 3756 were female students. Randomly selected female students in private college in Gondar town were included in the study. Students incapable to fill the questionnaire were excluded from the study.

\subsection{Sample size determination}

The sample size was determined using single population proportions formula with the assumption of 95 $\%$ confidence interval, $5 \%$ margin of error, $74.17 \%$ of students who had positive attitude towards safe abortion was taken from previous study (15), and non-response rate of $10 \%$ was considered. Design effect of 2 was used to account for the stratified sampling involved. The final sample size was determined to be 648 .

\subsection{Sampling technique}

To obtain the required sample size, stratified random sampling was applied to select study participants from the source population. First students were stratified by their department. Then, sample size was proportionally allocated to all the departments in the institutions based on the number of female students in each department. Sample was collected from all departments by computer generated simple random sampling method from list of female students obtained from the principal office.

\subsection{Data collection method}

The data was collected by using structured and self-administered questionnaires that was designed by reviewing from previous similar studies $(7,8,12,15,16)$. The questionnaire was prepared in English. The questionnaire consists of all the variables that can meet the objectives of the study which is related to sociodemographic characteristics, knowledge and attitude towards safe abortion. Data collectors were selected from health professionals of University of Gondar comprehensive specialized hospital. Data collectors were given training before actual data collection was commenced. The data was collected while students were in class rooms. The completed questionnaires were checked for completeness by the investigators.

\subsection{Study Variables and Measurements}

The study assessed the knowledge and attitude of participants towards safe abortion. Students' knowledge regarding safe abortion score was calculated out of the 21 knowledge specific questions. Each correct response earned one point and zero for the incorrect one based on the respondent's response. Finally, the respondent who scored greater than or equal to the mean score were considered as 
having 'good knowledge' and respondents who scored less than the mean score were considered as having 'poor knowledge'.

Students' attitude towards safe abortion score was calculated out of 11 specific questions. The respondents who scored greater than or equals to the mean score were considered as having 'favorable attitude' and those who scored less than the mean score was considered as having 'unfavorable attitude'. The independent variables were: age, sex, religion, marital status, place of previous resident (either urban or rural), year of study and income from family.

\subsection{Data quality control}

A pre-test of the data collection tool was carried out. Training was given to the data collectors before the data collection on objectives of the study, procedure of data collection, ethical consideration, data quality control and other related issue like confidentiality. Before the beginning, the respondents were told about the objective of the study and their importance to participate voluntarily in the study. The collected data were checked for completeness and consistency, on daily basis. Data was kept in the form of file in a private secured place and confidentiality was insured by not recording names or any personal identity.

\subsection{Data processing and analysis}

Data were coded, entered and cleaned using EPIINFO version 3.5.3 and then transported to SPSS version 20 for further statistical analysis. Frequencies, percentages and mean were computed to describe the key variables of the study. Bivariable and multivariable analysis were used to determine the association between different factors and the outcome variables. Forward model building procedure was used to select variables. Those variables having $p$-value $<0.2$ in the bivariable analysis were included in multivariable analysis and variables having $p$-value $<0.05$ in the multivariable were considered as statically significant. Odds ratio and the respective $95 \%$ confidence intervals were used to assess the strength of association between the variables.

\section{Result}

3.1 Socio- demographic characteristics of respondents

A total of 633 respondents participated in this study making the response rate of $97.7 \%$. The mean age was 21.8 years (SD \pm 2.99 ). Regarding to ethnicity, 588 (92.9\%) of participants were Amhara. Majority, $425(67.2 \%)$ of the students were Orthodox religion followers. Four hundred ninety-five $(78.2 \%)$ of students reported that they were living in urban area before they joined to the college. Nearly two third, $389(61.5 \%)$ of students were single never been in relationship. Concerning family education, $338(53.4 \%)$ of them were from both illiterate parents. The monthly incomes send from the family of the $71.6 \%$ students were less than $600 \mathrm{Birr}(\mathrm{Table}-1)$.

3.2 Knowledge of respondents on safe abortion 
The overall knowledge of students regarding safe abortion was 433(68.4\%).Among respondents, 609 (96.2\%) had ever heard about safe abortion, from those 483(79.3\%) got information from health institutions(Figure 1).Unsafe abortion as a major health problem of Ethiopia was considered by 598 (80.3\%) of the participants. From the total participants, $452(71.4 \%)$ responded that Ethiopia has abortion law. Nearly half, 315 (49.9\%) of the respondents mentioned the place where safe abortion performed was in hospital. Among respondents, 376 (59.4\%) said less than 3 months of pregnancy is the preferable time to perform safe abortion. The students were asked to answer why abortion is legal in Ethiopia; $516(81.5 \%)$ mentioned when the pregnancy is extra marital and $492(77.7 \%)$ if she is financially unable to rise the child (Table 2).

\subsection{Attitudes of respondents on safe abortion}

Among the study participants, 361 (57\%) of respondent had positive attitude towards safe abortion. Majority, 531(83.9\%) of the respondents disagreed that elective abortion should be legal \& accessible under any circumstance. Majority, $461(72.8 \%)$ of respondents were disagreed with legalization of safe and voluntary abortion. Majority, 435(68.7\%) of them agreed as abortion services should be available at health center \&hospital. The finding also showed that $406(64.1 \%)$ of the respondents agreed that male/husbands should have influences in decision of abortion. More than half, 348(55\%) of the respondents agreed that adolescent students use induced abortions to terminate pregnancies (Table 3).

\subsection{Factors affecting students' knowledge towards safe abortion}

In the bivariate analysis, the factors that found to have an association with knowledge towards safe abortion among students were age, marital status, residence, family education, year of study and ever heard about abortion with a p-value $<0.2$. In the multivariate analysis age, family education, residence and ever heard about abortion had association with knowledge towards safe abortion.

Students who found in the age group of 25-30 were 2.81 times more likely to have good knowledge on safe abortion compared to those whose age found in $18-24$ ( $\mathrm{AOR}=2.81,95 \% \mathrm{Cl}$ : 1.13, 7.47). Those respondents who came from urban area were 2.33 times more knowledgeable as compared to those living in rural areas $(\mathrm{AOR}=2.33,95 \% \mathrm{Cl}: 1.22,4.46)$. Respondents with both parent literates were 3.29 times more likely to have good knowledge on safe abortion compared to their counter parts (AOR $=3.29$, $95 \% \mathrm{Cl}: 1.22,6.46)$. Students who ever heard about safe abortion were 4.31 times more likely to have good knowledge compared with those who did not heard about safe abortion ( $A O R=4.31,95 \% \mathrm{Cl}$ : 1.79 , 10.33)(Table 4).

\subsection{Factors affecting students' attitude towards safe abortion}

Regarding attitude, age, religion, family education, residence and marital status had association with attitude towards safe abortion in bivariable analysis. All explanatory variables which were considered in the bivariate analyses were included in the multivariable logistic regression. Accordingly, age of 
respondents and place of residence were remained to be significantly associated with attitude of students towards safe abortion.

Students who found in the age group of 25-30 were 2.62 times more likely to have favorable attitude towards safe abortion compared to those whose age found in 18-24 (AOR $=2.62,95 \% \mathrm{Cl}: 1.70,4.04)$. Those students from urban residents were 1.5 more likely to have favorable attitude towards safe abortion compared to rural residents $(\mathrm{AOR}=1.50,95 \% \mathrm{Cl}: 1.04,2.17)$ (Table 5).

\section{Discussion}

Assessment of knowledge, attitude and associated factors towards safe abortion among students is important to minimize the burdens associated with unsafe abortion. This study revealed that the overall knowledge of students regarding to safe abortion was $68.4 \%$ (95\% Cl: $64.8,72.4)$. This finding is consistent with other study done in in Kampala, Uganda (12)which documented $72.4 \%$ of students had good knowledge towards safe abortion. However, this finding was higher than studies conducted in Mekelle University, Northern Ethiopia(7),WolaitaSodo University, Southwest Ethiopia(17) and in Puducherry, India (18) where the knowledge of students was reported as $44.1 \%, 38.8 \%$ and $36 \%$ respectively. The reason for this variation might be due to difference in study participants, only first year students were included in these studies, where as in this study participants includes were first year and above. It is fact that as the year of study increases the level of knowledge of students also increased (19). Moreover, the variation might be occurred due to difference in access to health information in different settings.As the study conducted in Mizan-Tepi University, South West Ethiopia, among Female Students $90.52 \%$ had adequate knowledge regarding safe abortion(15); which is higher than this finding.

In the present study, students who found in the age group of 25-30 were 2.62 more likely to have adequate knowledge regarding safe abortion as compared to those whose age found in 18-20.This finding is in line with a cross sectional study conducted in Kampala, Uganda (12). The possible explanation might be the fact that as age increases student's exposure to information regarding safe abortion could also increase.

This study also showed that students who came from urban area were more knowledgeable as compared to those living in rural areas. This may be because of the fact that urban dwellers have an opportunity to access information and educational media. Respondents with both parent literates were more than three times more likely to have good knowledge on safe abortion compared to their counter parts. This finding was supported by studies done in Mekelle University, Northern Ethiopia(7) and University of Buenos Aires, Argentina(20). This is may be due to the fact that parents having higher educational background let their children know additional and important lesson beside the academic program.

This study revealed that students who ever heard about safe abortion were more likely to have good knowledge compared with those who did not hear about safe abortion. This finding is in agreement with other studies conducted in Mizan-Tepi University, Ethiopia (15) and South Africa (21). The explanation for this might be that students, who have different information regarding health problems of unsafe abortion, 
could have increased awareness related to major obstacles for their education and other health related problems. Further, students are becoming more accessed to different mass media and getting more information about the problem, may have expected good knowledge regarding safe abortion. In addition to this youth friendly service and youth center are limited to the urban area, which can increase the access for the reproductive information and service.

In this study $57 \%(95 \% \mathrm{Cl}: 52.6,60.8)$ of students had positive attitude towards safe abortion. This result is supported by a study done in Mekelle University, Ethiopia which showed nearly half of the students $52.8 \%$ have positive attitude towards safe abortion (7). This finding is lower than other cross-sectional studies conducted in Mizan-Tepi University (15)and South Africa (21)which reported as $74.17 \%$ and $70 \%$ of students had positive attitude towards safe abortion, respectively. This result is higher than a cross sectional study conducted in Somali Region, Ethiopia that revealed $40.7 \%$ of students had favorite attitude towards safe abortion (16). The reason for this variation may be due to cultural beliefs and socioeconomic status.

According to this study, students who found in the age group of 25-30 were 2.62 times more likely to have favorable attitude towards safe abortion compared to those whose age found in 18-24. This finding is supported by previous study conducted among medical school students in South Africa(21). This study also showed that students from urban residents before joining to college were more likely to have favorable attitude towards safe abortion as compared to rural residents. This finding is in agreement with a cross sectional study conducted Somali Region(16), Mekelle University(7); Ethiopia and Kampala, Uganda (12).

This study has some limitations; it was assessed both health science and non-health science students together without separating by department, and even the study touches sensitive issues qualitative study was not done. The other limitation the study is it does not include governmental owned college and university students, and sociocultural factors were not assessed.

\section{Conclusion}

In conclusion, this study revealed that more than two-third of participants had good knowledge and more than half of the participants had favorable attitude regarding to safe abortion. But, still significant proportion of students had poor knowledge and unfavorable attitude towards safe abortion. Moreover, age of students, residence, family education, and ever heard about abortion were factors that associated with knowledge on safe abortion. Age of students and residence had an association with attitude towards abortion. Therefore, information, education and communications programs on youth reproductive health should be provided to address topics on safe abortion for all College students. Forums and panel discussions on safe abortion need to be undertaken especially, among youths and students who came from rural area. Youth friend service has to expand to the rural part of Ethiopia.

\section{List Of Abbreviations}




\section{COR: crude odds ratio, AOR: adjusted odds ratio, Cl: confidence Interval, SPSS: Statistical Package for Social Science, WHO: World Health Organization}

\section{Declarations}

\section{Acknowledgment}

The authors acknowledge the University of Gondar for approval of ethical issues. The authors would also like to thank all study participants for their commitment in responding to the questionnaire.

\section{Funding}

No funding has been obtained from any source to carry out this study.

\section{Availability of data and material}

The datasets used and analyzed during the current study are available from the corresponding author.

\section{Authors' contributions}

BDM wrote the proposal, participated in data collection, analysis, report writing and drafted the manuscript. CAW made revisions on proposal, participated in data analysis and drafted the manuscript. All authors reviewed, revised and approved the manuscript for publication.

\section{Ethics approval and consent to participate}

Ethical clearance was obtained from research review committee of College of Medicine and Health sciences, University of Gondar. Official letter was written from University of Gondar, College of Medicine and Health sciences to each college where the study was conducted. The objective of the study was discussed to the students; then verbal informed consent was obtained from the study participants. They were informed to have the right not to participate on the study, if they were not interested to involve on it. Confidentiality of information was maintained by omitting any personal identifier from the questionnaire.

\section{Consent for publication}

It is not applicable

\section{Competing interests}


The authors declare that they have no competing interests.

\section{References}

1. A. Mark (Ed.). Chapel Hill NI. Clinical Updates in Reproductive Health (July 2013 ed.). Ipas. 2013.

2. (WHO) WHO. Safe abortion: Technical and policy guidelines for health system (2nd ed.). Geneva, Switzerland:. (2012b).

3. (WHO) WHO. Unsafe abortion: Global and regional estimates of the incidence of unsafe abortion and associated mortality in (6th ed.). Geneva, Switzerland:. (2011).

4. Moore AM GY, Fetters T, et al. The Estimated Incidence of Induced Abortion in Ethiopia, Changes in the Provision of Services Since 2008. . Int Perspect Sex Reprod Heal Heal 2016;42(3):111-120. 2014.

5. Shah I ÅE. Unsafe Abortion: Global and Regional Incidence, Trends, Consequences, and Challenges. J Obstet Gynaecol Can;31(12):1149-1158. 2010.

6. Gelaye AA, Taye KN, Mekonen T. Magnitude and risk factors of abortion among regular female students in Wolaita Sodo University, Ethiopia. BMC women's health. 2014;14(1):50.

7. Selam Desalegn AD, Azeb G/selassie, Amanuel Tesfay, Robel Abaya. knowledge, attitude and factors associated with safe abortion among first year students in Mekelle University, Tigray, Ethiopia. International Journal of Pharma Sciences and Research (IJPSR). 2015;Vol 6 No 01

8. Rahel Y DA, Asrat M. Knowledge, Attitude and Practice towards Induced Abortion and Associated Factors among Female students in Yebu Secondary School, Jimma zone, South West Ethiopia. Glob J Reprod Med. 2018; 5(2): 555659.

9. K. L. Turner \& A. Huber (Eds.). Chapel Hill NI. Woman-centered comprehensive abortion care: Reference manual(2nd ed.). Ipas. (2013c).

10. (WHO) WHO. Unsafe abortion: global and regional estimates of the incidence of unsafe abortion and associated mortality in 2008. 6th edn. Geneva: . WHO. 2011.

11. Yogi A. Prevalence and factors associated with abortion in Nepal: A national cross-sectional study 2016.

12. Paluku JL, Kalisoke S, Julius W, Kiondo P. Knowledge and attitudes about induced abortions among female youths attending Naguru Teenage Information and Health Centre, Kampala, Uganda. Journal of Public Health and Epidemiology. 2013;5(4):178-85.

13. Cadmus EO OE. Knowledge about complications and practice of abortion Among female undergraduates in the university of ibadan, Nigeria. Ann Ibd Pg Med. 2011.;Vol.9, No.1 19-23.

14. Mirembe F KJ, Hassan EO, Faúndes A Goals and activities proposed by countries in seven regions of the world toward prevention of unsafe abortion. Int J Gynaecol Obstet 2010;110:S25-9.

15. Mekuriaw S, Mesay R, Dereje A, Kumalo A, Feyissa M. Knowledge, Attitude and Practice towards Safe Abortion among Female Students of Mizan-Tepi University, South West Ethiopia. J Women's Health Care. 2015;4(275):2167-0420.1000. 
16. Dhar G. Knowledge, Attitude and Associated Factors towards Safe Abortion among Female Students of Kebribayah Town of Somali Region, Ethiopia.

17. Amha Admasie Gelaye KNTaTM. Magnitude and risk factors of abortion among regular female students in Wolaita Sodo University, Ethiopia. BMC Women's Health 2014, 14:50.

18. Palo LB, Chauhan NS, Parvathi T, Chauhan RC. Awareness regarding abortions and medical termination of pregnancy act among medical students in Puducherry, India. International Journal of Research in Medical Sciences. 2017;3(10):2729-33.

19. Tara A. Norman W, Knowledge-Assessment Survey of Undergraduate Medical Students. University of British Columbia: Vancouver BC; may2010.

20. Brodahl A, Jarlsdatter Hovind M. Knowledge and attitudes towards abortion among the first year medical students. Argentina: University of Buenos Aires; 2011/2012.

21. Wheeler SB, Zullig LL, Reeve BB, Buga GA, Morroni C. Attitudes and intentions regarding abortion provision among medical school students in South Africa. International perspectives on sexual and reproductive health. 2012;38(3):154.

\section{Tables}

Table1: Socio demographic characteristic of private college students in Gondar town, northwest Ethiopia, $2019(n=633)$ 


\begin{tabular}{|c|c|c|}
\hline Variables & Frequency & Percent \\
\hline \multicolumn{3}{|l|}{ Age } \\
\hline $18-24$ & 498 & 78.7 \\
\hline $25-30$ & 135 & 21.3 \\
\hline \multicolumn{3}{|l|}{ Religion } \\
\hline Orthodox & 425 & 67.2 \\
\hline Muslim & 138 & 21.8 \\
\hline Protestant & 43 & 6.7 \\
\hline Other & 27 & 4.3 \\
\hline \multicolumn{3}{|l|}{ Marital status } \\
\hline Single, never in relationship & 389 & 61.5 \\
\hline Single, no current relationship & 81 & 12.8 \\
\hline Single, in relationship & 80 & 12.6 \\
\hline Married & 83 & 13.1 \\
\hline \multicolumn{3}{|l|}{ Family education } \\
\hline Both illiterate & 338 & 53.4 \\
\hline One literate, one illiterate & 214 & 33.8 \\
\hline Both literate & 81 & 12.8 \\
\hline \multicolumn{3}{|l|}{ Residence } \\
\hline Rural & 495 & 78.2 \\
\hline Urban & 138 & 21.8 \\
\hline \multicolumn{3}{|l|}{ Ethnicity } \\
\hline Amhara & 588 & 92.9 \\
\hline Other & 45 & 7.1 \\
\hline \multicolumn{3}{|l|}{ Department } \\
\hline Nursing & 212 & 33.5 \\
\hline Pharmacy & 143 & 22.6 \\
\hline Accounting & 138 & 21.8 \\
\hline Management & 94 & 14.8 \\
\hline Other & 46 & 7.3 \\
\hline \multicolumn{3}{|l|}{ Year of study } \\
\hline $1^{\text {st }}$ year & 143 & 22.6 \\
\hline $2^{\text {nd }}$ year & 207 & 32.7 \\
\hline $3^{\text {rd }}$ and above & 283 & 44.7 \\
\hline \multicolumn{3}{|l|}{ Monthly income sends from family } \\
\hline$<600$ & 453 & 71.6 \\
\hline $601-1000$ & 143 & 22.6 \\
\hline$>1001$ & 37 & 5.8 \\
\hline
\end{tabular}

Table2: Knowledge regarding safe abortion among private college students in Gondar town, northwest Ethiopia, 2019 ( $\mathrm{n}=633)$ 
Have you ever Heard about method of abortion?

No

Where safe abortion service conducted

Hospital

Health center

Private clinic

Home

jafe abortion service will reduce the risk of women 's Reproductive health

oroblem

Yes

No

I don't know

When is the preferable time to perform safe abortion?

Before 3 months of pregnancy

At any time during pregnancy

s unsafe abortion considered major Problem, today?

Yes

No

تthiopia has abortion law?

Yes

No

For what reason is abortion legal in Ethiopia

Not allowed for any reason in Ethiopia

If pregnancy is due rape or incent

If pregnancy endangers Life of woman or fetus.

For woman with physical/ mental disabilities

For woman physically psychologically un prepared

If she is financially unable to rise the child

When pregnancy the pregnancy is extra marital
315

143

111

53

213

284

136

49.8

22.6

17.5

8.4

33.6

44.9

21.5

376

59.4

257

40.6

508

125

80.3

19.7

452

181

71.4

28.6

204

32.2

326

51.5

264

41.7

359

56.7

455

71.9

492

77.7

516 


\begin{tabular}{|c|c|c|}
\hline iables & $\begin{array}{l}\text { Disagree } \\
\mathbf{N}(\%)\end{array}$ & $\begin{array}{l}\text { Agree } \\
\text { N (\%) }\end{array}$ \\
\hline e and voluntary abortion should be legal and accessible & $461(72.8)$ & $172(27.2)$ \\
\hline ctive abortion should be legal $\&$ accessible under any circumstance & $531(83.9)$ & $102(16.1)$ \\
\hline $\begin{array}{l}\text { Joman under } 18 \text { requesting safe abortion service should terminate } \\
\text { gnancy }\end{array}$ & $426(67.3)$ & $207(32.7)$ \\
\hline e abortion is acceptable if she is financially unable to rise the child & $431(68.1)$ & 202(31.9) \\
\hline e abortion is acceptable to prevent mother's life or fetal anomaly & $361(57.0)$ & $272(43.0)$ \\
\hline $\begin{array}{l}\text { s acceptable for woman to choose safe abortion because of rape or } \\
\text { ent }\end{array}$ & $308(48.7)$ & $325(51.3)$ \\
\hline Ivision of safe abortion after Unwanted Pregnancy can prevent & & \\
\hline thers' life? & $271(42.8)$ & $362(57.2)$ \\
\hline le/ husbands' have influences in decision of aborting & $227(35.9)$ & $406(64.1)$ \\
\hline e abortion services should be available at health center \&hospital? & 198(31.3) & $435(68.7)$ \\
\hline man has the right to terminate her Pregnancy if she wishes? & $290(45.8)$ & $343(54.2)$ \\
\hline & $285(45.0)$ & $348(55.0)$ \\
\hline
\end{tabular}

Table4: Factors associated with knowledge of female students towards safe abortion, in Gondar town, northwest Ethiopia, 2019 


\begin{tabular}{|c|c|c|c|c|}
\hline \multirow[t]{2}{*}{ Variables } & \multicolumn{2}{|c|}{ Knowledge } & \multirow{2}{*}{$\begin{array}{l}\text { Crude } \\
\text { OR(95\% CI) }\end{array}$} & \multirow{2}{*}{$\begin{array}{l}\text { Adjusted } \\
\text { OR(95\% CI) }\end{array}$} \\
\hline & Good & Poor & & \\
\hline \multicolumn{5}{|l|}{ tge } \\
\hline $18-24$ & 349 & 149 & 1 & \\
\hline $25-30$ & 84 & 51 & $1.42(0.96,2.12)$ & $2.81(1.13,7.47)$ \\
\hline \multicolumn{5}{|l|}{ Marital status } \\
\hline Single, never in relationship & 274 & 115 & 1 & 1 \\
\hline Single, no current relationship & 61 & 20 & $0.78(0.45,1.35)$ & $0.73(0.39,1.34)$ \\
\hline Single, in relationship & 45 & 35 & $1.85(1.13,3.03)$ & $1.83(0.96,3.29)$ \\
\hline Married & 53 & 30 & $1.35(0.82,2.22)$ & $1.78(0.89,2.43)$ \\
\hline \multicolumn{5}{|l|}{ Family education } \\
\hline Both illiterate & 223 & 115 & 1 & 1 \\
\hline One literate, one illiterate & 149 & 65 & $0.85(0.59,1.22)$ & $0.95(0.62,1.47)$ \\
\hline Both literate & 61 & 20 & $1.64(1.10,3.27)$ & $3.29(1.22,6.46)$ \\
\hline \multicolumn{5}{|l|}{ Residence } \\
\hline Rural & 342 & 153 & 1 & 1 \\
\hline Urban & 91 & 47 & $1.15(0.77,1.72)$ & $2.33(1.22,4.46)$ \\
\hline \multicolumn{5}{|l|}{ Year of study } \\
\hline $1^{\text {st }}$ year & 99 & 44 & 1 & 1 \\
\hline $2^{\text {nd }}$ year & 93 & 114 & $2.76(1.57,4.14)$ & $0.69(0.39,1.27)$ \\
\hline $3^{\text {rd }}$ and above & 241 & 42 & $0.39(0.24,0.64)$ & $1.29(0.82,2.03)$ \\
\hline \multicolumn{5}{|l|}{ Ever heard about abortion } \\
\hline Yes & 424 & 185 & $3.82(1.64,8.89)$ & $4.31(1.79,10.33)$ \\
\hline No & 9 & 15 & 1 & 1 \\
\hline \multicolumn{5}{|l|}{ Monthly income sent from family } \\
\hline$<600$ & 301 & 152 & 1 & 1 \\
\hline $601-1000$ & 103 & 40 & $0.71(0.51,1.16)$ & $0.99(0.42,2.31)$ \\
\hline$>1001$ & 29 & 8 & $0.61(0.24,1.22)$ & $0.89(0.68,4.24)$ \\
\hline
\end{tabular}

Table5: Factors associated with attitude of female students towards safe abortion in Gondar town, northwest Ethiopia, 2019 


\begin{tabular}{|c|c|c|c|c|}
\hline \multirow[t]{2}{*}{ :iables } & \multicolumn{2}{|c|}{ Attitude } & \multirow{2}{*}{$\begin{array}{l}\text { Crude } \\
\text { OR }(95 \% \mathrm{CI})\end{array}$} & \multirow{2}{*}{$\begin{array}{l}\text { Adjusted } \\
\text { OR(95\% CI) }\end{array}$} \\
\hline & Favorable & Unfavorable & & \\
\hline \multicolumn{5}{|l|}{100} \\
\hline $18-24$ & 297 & 201 & 1 & 1 \\
\hline $25-30$ & 64 & 71 & $1.64(1.12,2.41)$ & $2.62(1.70,4.04)$ \\
\hline \multicolumn{5}{|l|}{ ligion } \\
\hline Orthodox & 309 & 116 & 1 & 1 \\
\hline Muslim & 39 & 99 & $6.76(4.41,10.37)$ & $2.09(0.83,9.22)$ \\
\hline Protestant & 6 & 37 & $16.43(6.76,19.9)$ & $3.87(0.94,8.31)$ \\
\hline Other & 7 & 20 & $7.61(3.12,18.47)$ & $1.74(0.49,6.08)$ \\
\hline \multicolumn{5}{|l|}{ rital status } \\
\hline Single, never in relationship & 198 & 191 & 1 & 1 \\
\hline Single, no current relationship & 63 & 18 & $0.29(0.17,1.03)$ & $2.49(0.74,4.30)$ \\
\hline Single, in relationship & 44 & 36 & $0.85(0.52,1.38)$ & $0.78(0.37,1.64)$ \\
\hline Married & 56 & 27 & $0.50(0.31,0.82)$ & $1.59(0.81,3.14)$ \\
\hline \multicolumn{5}{|l|}{ nily education } \\
\hline Both illiterate & 184 & 154 & 1 & 1 \\
\hline One literate, one illiterate & 126 & 88 & $0.83(0.59,1.18)$ & $0.94(0.55,1.61)$ \\
\hline Both literate & 51 & 30 & $0.70(0.43,1.16)$ & $1.03(0.59,1.81)$ \\
\hline \multicolumn{5}{|l|}{ sidence } \\
\hline Rural & 289 & 206 & 1 & 1 \\
\hline Urban & 72 & 66 & $1.29(0.88,1.88)$ & $1.50(1.04,2.17)$ \\
\hline
\end{tabular}

\section{Figures}

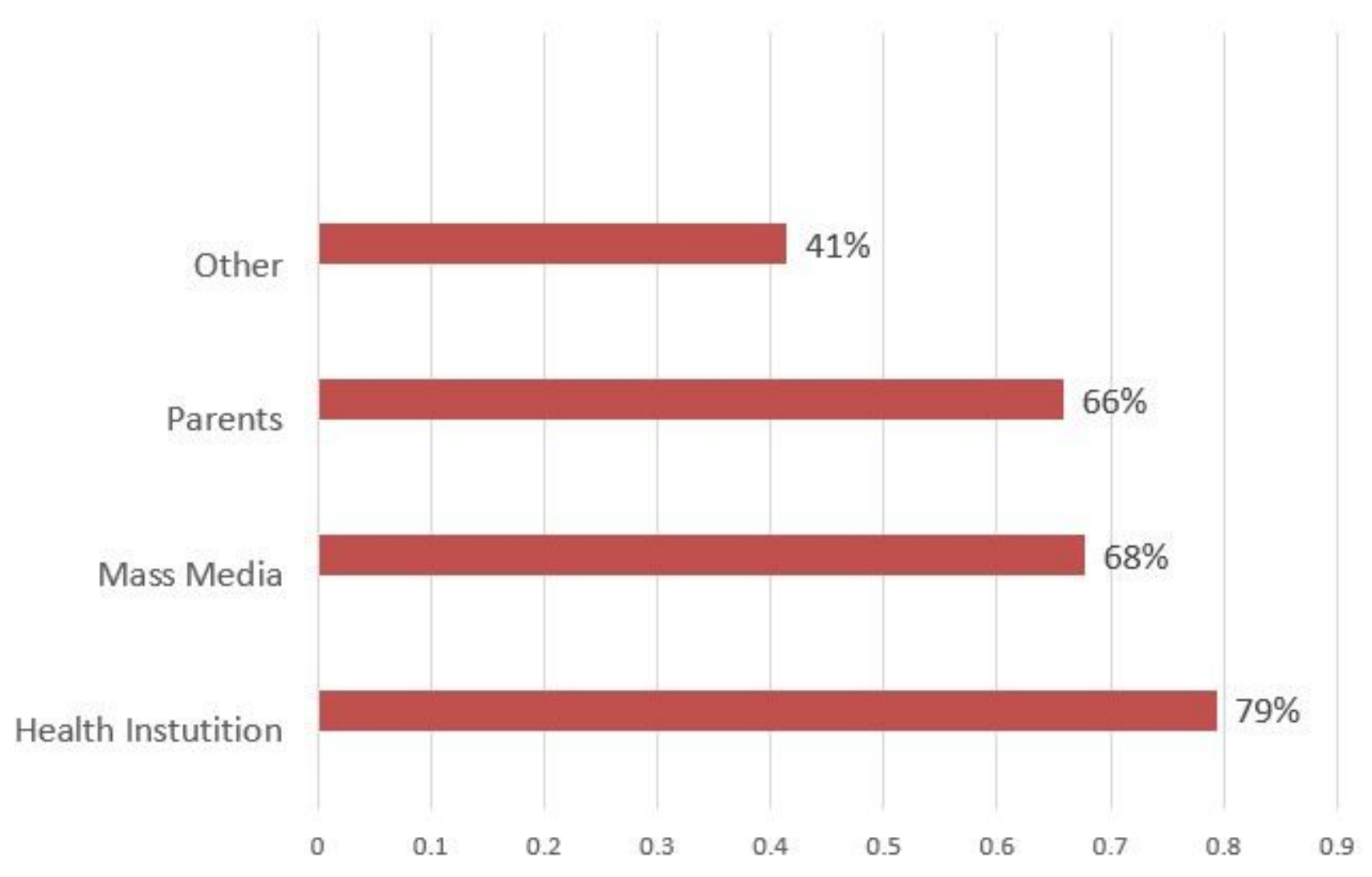




\section{Figure 1}

Source of information about safe abortion among private college students in Gondar town, northwest Ethiopia, 2019 